\title{
Association between the occurrence of growing pains and vitamin-D deficiency in Indian children aged 3-12 years
}

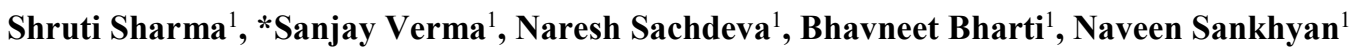

Sri Lanka Journal of Child Health, 2018; 47(4): 306-310

\begin{abstract}
Introduction: Growing pains (GP) is a wellrecognized entity in children aged 3-12 years. Its diagnosis is based on Peterson criteria. The exact aetiology of GP is not known; however, some studies have linked GP and vitamin-D deficiency.

Objective: To find out the association between occurrence of GP and vitamin-D deficiency (VDD) in Indian children aged 3-12 years.
\end{abstract}

Method: Children presenting with GP, fulfilling Peterson criteria, were enrolled in the study group, along with an equal number of age and sex matched healthy controls. Analysis of serum calcium, phosphorus, alkaline phosphatase and serum 25-hydroxy-vitamin-D [25(OH)D] levels were done. The results of cases and controls were compared; those children found to have VDD were supplemented with Vitamin-D and response in pain was noted after one month.

Results: Forty five children each were enrolled in the GP and control group. Prevalence of VDD in GP group was (41/45) $91.1 \%$ and in control group (26/45) $57.8 \%$ [p-value $0.001, \mathrm{RR}=7.490 ; 95 \%$, $\mathrm{CI}=2.290-24.496]$. The mean value of serum calcium, phosphorus, alkaline phosphatase in GP group were $9.50 \mathrm{mg} \%, 5.15 \mathrm{mg} \%, 271 \mathrm{IU} / \mathrm{L}$; while in the control group they were $8.84 \mathrm{mg} \%, 4.72$ $\mathrm{mg} \%, 216.2 \mathrm{IU} / \mathrm{L}$ respectively. At one month follow-up of GP group, (31/45) 68.9\% became asymptomatic while remaining 14 children showed improvement in symptoms.

Conclusions: Children, 3-12 years old, presenting with GP are more likely to have VDD compared to children without GP.

DOI: http://dx.doi.org/10.4038/sljch.v47i4.8590

\footnotetext{
${ }^{1}$ Postgraduate Institute of Medical Education and Research, Chandigarh, India

*Correspondence: sanjay06verma@yahoo.com (Received on 04 December 2017: Accepted after revision on 19 January 2018)

The authors declare that there are no conflicts of interest

Personal funding was used for the project.

Open Access Article published under the Creative
}

Commons Attribution CC-BY (cc) (i)
(Key words: Growing pains, vitamin-D deficiency, Indian children)

\section{Introduction}

Growing pains (GP) is a well-recognized entity in children usually found in the age group of 3-12 years $^{1-3}$. Its diagnosis remains clinical, based on Peterson criteria comprising bilateral, intermittent, non-articular pain in lower limbs, characteristically occurring in the evening. The physical examination and laboratory parameters are normal, whenever performed $^{4}$. Prevalence of GP ranges from 3 to $50 \%$ in different studies ${ }^{2,5,6}$. In the past, the strain of the muscles attached to growing bones and muscle fatigue have been believed to cause $\mathrm{GP}^{1}$. Various psychological and familial factors have also been implicated ${ }^{7}$. Even after almost two centuries of its first description in 1823, the aetiology of GP remains poorly understood ${ }^{5}$.

Several decades ago, GP was said to be a manifestation of calcium deficiency by Abraham Jacobi ${ }^{8}$. James Dowd, in a blog on vitamin-D, said that "growing pains are a clinical expression of hypovitaminosis $\mathrm{D}^{\prime 8}$. There is little knowledge about the association between vitamin-D deficiency (VDD) and GP in children. VDD is widely prevalent in children of Northern India without overt clinical or biochemical evidence of rickets ${ }^{9,10}$. Non availability of vitamin-D fortified food products, vegetarian Indian diets and decreased sun exposure in affluent children may be responsible for the hypovitaminosis- $\mathrm{D}^{10}$.

\section{Objectives}

The primary objective of the study was to compare the VDD status of children presenting with GP with that of healthy controls. Secondary objectives were to compare the mean levels of serum calcium, phosphorus and alkaline phosphatase in both groups.

\section{Method}

This cross-sectional study was conducted over a one-year period (January- December 2013) at the out-patient department (OPD) in a tertiary care hospital in Northern India. Ethical clearance was obtained from the Institute Ethics committee before starting the study. Children, 3-12 years old, attending the paediatric OPD with complaints of GP, fulfilling Peterson's diagnostic criteria, were enrolled into our study after obtaining informed 
written consent. Children with known organic cause for pain like a rheumatologic disorder, with chronic systemic illnesses and who have received any vitamin-D supplementation in past one year were excluded from the study. An equal number of healthy children (age and sex matched) who were visiting the hospital for routine health check-ups with no history of GP were recruited as controls. After enrolment, a pre-designed questionnaire was filled in by the investigator containing information regarding baseline demographic and socio-cultural details. Clinical characteristics of GP were also recorded. Three millilitre venous blood was collected from enrolled children (cases and controls) for analysis of serum calcium (Ca), phosphorus (P) and alkaline phosphatase (ALP) using kits and calibrators and control from the same supplier [Dimension RxL Max clinical chemistry analyser using specific kits] and serum 25-hydroxy-vitamin-D (25-(OH)D) [Electrochemiluminescence immunoassay i.e. ECLIA Roche Diagnostics, Germany]. Serum 25-(OH)D level of $<20 \mathrm{ng} / \mathrm{ml}$, was considered deficient; a level of 20 to $\leq 30 \mathrm{ng} / \mathrm{ml}$, insufficient; and a level of $>30 \mathrm{ng} / \mathrm{ml}$, was considered optimal ${ }^{9}$.

Sample size: Keeping assumptions as VDD among controls $35 \%$, matching $1: 1$, power $90 \%$, alpha error $5 \%$, sample size was calculated by 45 per group (total 90 children).

Statistical analysis: Descriptive statistics were used to describe baseline variables. The quantitative variables were reported as mean and SD while qualitative variables were reported as proportions. Normal distribution variables were compared by Student's t-test after evaluating equality of variance by Levene's test whereas skewed variables were analysed with an appropriate non-parametric test. A $p$-value (two-tailed) of less than 0.05 was taken as significant. Data was analysed by using SPSS version 14.0, Chicago, Illinois, USA).

\section{Results}

This study included a total of 90 children i.e. 45 cases and 45 age and sex matched controls. Mean age in cases and controls was 6.3 years. Regarding sex distribution, the cases and control groups had equal proportions (22 males and 23 females). Baseline parameters were comparable in both groups. GP was mainly in the lower limbs (legs and thighs) in most of the children. It was present mainly during evening or night in $75.6 \%$ children. Interventions like local leg massage for relieving this pain was done by the majority i.e. 34 children $(75.6 \%)$. Other measures were massage and analgesics in four; massage and heat packs in two, analgesics alone in three and no treatment in two children. Behavioural abnormalities were seen in only one child who had aggressive behaviour. An attempt to evaluate any association of GP with hypermobility was made using Beighton Score which uses a 9-point system score for hypermobility ${ }^{11}$. A score of 6 or more indicates hypermobility. In our study $12(26.7 \%)$ children in GP group and $8(17.8 \%)$ in control group had a score above $6(\mathrm{p}=0.3)$.

Prevalence of VDD in GP group was $91.1 \%$ $(41 / 45)$ and in the control group, it was $57.8 \%$ $(26 / 45)$ as shown in Table 1.

Nine percent $(4 / 45)$ of the children in GP group and $20 \%(9 / 45)$ in control group had insufficient levels of $25-(\mathrm{OH}) \mathrm{D}$ levels as shown in Figure 1.

Table 1: Proportion of children with vitamin-D deficiency (25-(OH)D) in study and control groups

\begin{tabular}{|c|c|c|c|}
\hline $\begin{array}{c}\text { Growing pains Group (n=45) } \\
\text { No. }(\%)\end{array}$ & $\begin{array}{c}\text { Control Group (n=45) } \\
\text { No. }(\%)\end{array}$ & RR (95\% CI) & p value \\
\hline $41(91.1)$ & $26(57.8)$ & $7.490(2.290-24.496)$ & 0.001 \\
\hline
\end{tabular}



Figure 1: Vitamin D status of cases (Growing Pains group) and controls 
The mean value of serum calcium in $\mathrm{mg} / \mathrm{dl}$ among children with GP was 9.5, while in the control group it was $8.8(\mathrm{p}=0.001)$. The mean value of serum phosphorus in $\mathrm{mg} / \mathrm{dl}$ among children with GP was 5.1, while in the control group, it was 4.7 $(\mathrm{p}=0.013)$. The mean value of serum ALP in $\mathrm{U} / \mathrm{L}$ among children with GP was 271.9, while in the control group it was $216.2(\mathrm{p}=0.011)$ as shown in Table 2.

Table-2: Comparison of anthropometry and biochemical parameters in study and control groups

\begin{tabular}{|l|c|c|c|}
\hline \multicolumn{1}{|c|}{ Variable } & $\begin{array}{c}\text { Growing pains group }(n=45) \\
\text { mean } \pm \text { SD }\end{array}$ & $\begin{array}{c}\text { Control group }(n=45) \\
\text { mean } \pm \text { SD }\end{array}$ & $p$ value \\
\hline Age (years) & $6.29 \pm 2.53$ & $6.29 \pm 2.53$ & 1.000 \\
\hline Present weight $(\mathrm{kg})$ & $20.00 \pm 6.70$ & $18.35 \pm 5.66$ & 0.210 \\
\hline Present height (metres) & $1.14 \pm 0.16$ & $1.11 \pm 0.15$ & 0.298 \\
\hline Body mass index & $15.07 \pm 2.13$ & $14.76 \pm 1.72$ & 0.455 \\
\hline $\begin{array}{l}\text { Serum calcium (mg/dl) } \\
\text { (Normal range=8.8-10.8) }\end{array}$ & $9.50 \pm 0.52$ & $8.84 \pm 0.91$ & 0.001 \\
\hline $\begin{array}{l}\text { Serum phosphorus }(\mathrm{mg} / \mathrm{dl}) \\
\text { (Normal range=3.8-6.5) }\end{array}$ & $5.15 \pm 0.84$ & $4.72 \pm 0.76$ & 0.013 \\
\hline $\begin{array}{l}\text { Serum alkaline phosphatase } \\
\text { (U/L) } \\
(\text { Normal range=145-420) }\end{array}$ & $271.95 \pm 109.04$ & $216.16 \pm 92.00$ & 0.011 \\
\hline $\begin{array}{l}25(\mathrm{OH}) \text { Vitamin D }(\mathrm{ng} / \mathrm{ml}) \\
(\text { Deficiency }<20)\end{array}$ & $11.47 \pm 6.43$ & $18.18 \pm 11.54$ & 0.001 \\
\hline
\end{tabular}

The mean value of $25-(\mathrm{OH}) \mathrm{D}$ in $\mathrm{ng} / \mathrm{ml}$ among children with GP was 11.5, while in the control group it was 18.2.

All children with insufficient or low vitamin-D levels were given 600,000 IU oral bolus vitamin-D (sachet Arachitol ${ }^{\circledR}$ 60,000 IU/sachet) along with oral calcium supplements (elemental Calcium 50 $\mathrm{mg} / \mathrm{kg} /$ day) for next 3 months. The children with GP (cases) were interviewed by making a telephone call after one month of vitamin-D bolus supplementation. Out of 45 enrolled children, 31 (68.9\%) became asymptomatic while 14 (31.1\%) children showed symptomatic improvement in pain. No adverse effect of oral supplementation was reported.

\section{Discussion}

In the present study, VDD was significantly commoner in children with GP in comparison with controls. None of the children with GP had vitamin-D levels $\geq 30 \mathrm{ng} / \mathrm{ml}$. This indicates that children with GP are 7 times more likely to have VDD compared to controls. A study from Pakistan (2011) showed $72 \%$ prevalence of VDD in children with GP, similar to our results ${ }^{12}$. Studies from Korea (2015) and Italy (2015) have also shown prevalence of VDD in children with GP to be $57.1 \%$ and $43.2 \%$ respectively ${ }^{13,14}$. There is a $57.2 \%$ prevalence of VDD and a $20 \%$ prevalence of vitamin D insufficiency in the control group, indicating widespread prevalence hypovitaminosis$\mathrm{D}$ in children in this region. In another study from same region, $76 \%$ of control subjects had VDD or insufficiency ${ }^{9}$. There are other studies from North India showing similar prevalence ${ }^{10,15-17}$.
GP in children could be an early manifestation of underlying histological changes in the bone matrix when routine biochemical markers are not markedly abnormal. Low serum concentrations of 25- $(\mathrm{OH}) \mathrm{D}$ with secondary hyperparathyroidism leads to decreased bone mineral density and resultant osteopenia ${ }^{18}$. With activity, the poorly mineralized bone matrix could hydrate and expands, causing an outward pressure on the periosteum, leading to pain ${ }^{19}$. A study by Uziael Y et al showed that in most patients, pain improvement paralleled increase in bone strength ${ }^{20}$. At one month follow-up after treatment of VDD, large majority of children showed clinical improvement in our study, as well. There are studies showing that low vitamin-D status adversely affects bone mass, bone turn-over and muscle strength in children, which could very well contribute to causation of GP in children ${ }^{21,22}$.

Regarding the secondary objective of our study, we found that controls had marginally lower mean levels of calcium and phosphorus. This could be a chance finding and did not correlate with the serum alkaline phosphtase levels. Since the majority of these biochemical markers were within normal range, $p$-value, though statistically significant, may not be of any clinical significance. Irrespective of the wide prevalence of VDD, these biochemical markers were not abnormal in the majority; that signifies the poor sensitivity of them in detecting VDD. Similar findings were also shown in a study from Tehran ${ }^{15}$. Other authors have also reported these biochemical markers of bone turnover to be unreliable even in the setting of secondary hyperparathyroidism ${ }^{16}$. 
The present study had certain limitations. The sample was drawn from a hospital visiting population and may not reflect the true community prevalence. Secondly, the sample size was small. The temperamental aspects and behavioural disturbances in children could have been more scientifically studied using rating scales or standardized questionnaires. Finally, the cause of GP could be multifactorial and as we only studied one association, a judgement on causation would be incorrect. Furthermore, larger studies would help in confirming the role of vitamin-D supplementation in reducing the incidence of BP.

\section{Conclusions}

Children (3-12 years) presenting with GP are more likely to have VDD compared to children without GP.

\section{References}

1. Uziel Y, Hashkes PJ. Growing pains in children. Pediatric Rheumatology Online Journal 2007;5:5.

https://doi.org/10.1186/1546-0096-5-5

PMid:17550631 PMCid:PMC1869025

2. Goodyear-Smith F, Arroll B. Growing pains. British Medical Journal (Clinical research ed) 2006; 333(7566):456-7. https://doi.org/10.1136/bmj.38950.463877 .80

PMid:16946319 PMCid:PMC1557982

3. Pavone V, Lionetti E, Gargano V, Evola FR, Costarella L, Sessa G. Growing pains: a study of 30 cases and a review of the literature. Journal of Pediatric Orthopedics 2011;31(5):606-9.

https://doi.org/10.1097/BPO.0b013e31822 0ba5e

PMid:21654473

4. Peterson H. Growing pains. Pediatric Clinics of North America 1986; 33(6): 1365-72.

https://doi.org/10.1016/S00313955(16)36 $147-8$

5. Evans AM. Growing pains: contemporary knowledge and recommended practice. Journal of Foot and Ankle Research 2008;1(1):4.

https://doi.org/10.1186/1757-1146-1-4

PMid:18822152 PMCid:PMC2553776

6. Oster J, Nielsen A. Growing pains. A clinical investigation of a school population. Acta Paediatrica Scandinavica 1972; 61(3):329-34. https://doi.org/10.1111/j.16512227.1972.t

b16108.x

PMid:5021456

7. Hashkes PJ, Friedland O, Jaber L, Cohen HA, Wolach B, Uziel Y. Decreased pain threshold in children with growing pains. The Journal of Rheumatology 2004; 31(3):610-3.

PMid:14994414

8. Bischoff HA, Borchers M, Gudat F, Duermueller U, Theiler R, Stahelin HB, et al. In situ detection of 1,25dihydroxyvitamin D3 receptor in human skeletal muscle tissue. The Histochemical Journal 2001; 33(1):19-24. https://doi.org/10.1023/A:1017535728844 PMid: 11352397

9. Borkar VV, Devidayal, Verma S, Bhalla AK. Low levels of vitamin D in North Indian children with newly diagnosed type 1 diabetes. Pediatric Diabetes 2010;11(5):345-50.

https://doi.org/10.1111/j.13995448.2009.0 0589.x

PMid: 19906128

10. Goswami R, Gupta N, Goswami D, Marwaha RK, Tandon N, Kochupillai N. Prevalence and significance of low 25hydroxyvitamin D concentrations in healthy subjects in Delhi. The American Journal of Clinical Nutrition 2000; 72(2): 472-5.

PMid: 10919943

11. Viswanathan V, Khubchandani RP. Joint hypermobility and growing pains in school children. Clinical and Experimental Rheumatology 2008; 26(5): 962-6.

PMid: 19032838

12. Qamar S, Akbani S, Shamim S, Khan G. Vitamin D levels in children with growing pains. Journal of the College of Physicians and Surgeons- Pakistan 2011; 21(5):284-7.

PMid: 21575536

13. Park MJ, Lee J, Lee JK, Joo SY. Prevalence of Vitamin D Deficiency in Korean Children Presenting with Nonspecific Lower-Extremity Pain. Yonsei Medical Journal 2015; 56(5):13848. 
https://doi.org/10.3349/ymj.2015.56.5.138 4

PMid: 26256984 PMCid: PMC4541671

14. Morandi G, Maines E, Piona C, Monti E, Sandri M, Gaudino R, et al. Significant association among growing pains, vitamin D supplementation, and bone mineral status: results from a pilot cohort study. Journal of Bone and Mineral Metabolism 2015; 33(2):201-6. https://doi.org/10.1007/s00774-014-05795

PMid: 24633492

15. Mohanta MP. Growing pains: practitioners' dilemma. Indian Pediatrics 2014; 51(5):379-83. https://doi.org/10.1007/s13312-014-04210

PMid: 24953579

16. Puri S, Marwaha RK, Agarwal N, Tandon N, Agarwal R, Grewal K, et al. Vitamin D status of apparently healthy schoolgirls from two different socioeconomic strata in Delhi: relation to nutrition and lifestyle. The British Journal of Nutrition 2008; 99(4): 876-82.

https://doi.org/10.1017/S00071145078317 58

PMid: 17903343

17. Jabbar Z, Aggarwal PK, Chandel N, Kohli HS, Gupta KL, Sakhuja V, et al. High prevalence of vitamin $\mathrm{D}$ deficiency in north Indian adults is exacerbated in those with chronic kidney disease. Nephrology (Carlton, Vic). 2009; 14(3):345-9. https://doi.org/10.1111/j.14401797.2008.0 1082.x

PMid: 19207865
18. McNally JD, Matheson LA, Rosenberg AM. Epidemiologic considerations in unexplained pediatric arthralgia: the role of season, school, and stress. The Journal of Rheumatology 2009; 36(2):427-33 PMid: 19040297

19. Lips P. Vitamin D physiology. Progress in Biophysics and Molecular Biology 2006; 92(1):4-8.

https://doi.org/10.1016/j.pbiomolbio.2006. 02.016

PMid: 16563471

20. Uziel Y, Chapnick G, Oren-Ziv A, Jaber L, Nemet D, Hashkes PJ. Bone strength in children with growing pains: long-term follow-up. Clinical and Experimental Rheumatology 2012; 30(1):137-40.

PMid: 22325064

21. Ward KA, Das G, Berry JL, Roberts SA, Rawer R, Adams JE, et al. Vitamin D status and muscle function in postmenarchal adolescent girls. The Journal of Clinical Endocrinology and Metabolism 2009; 94(2):559-63.

https://doi.org/10.1210/jc.2008-1284

PMid: 19033372

22. Foo LH, Zhang Q, Zhu K, Ma G, Hu X, Greenfield H, et al. Low vitamin D status has an adverse influence on bone mass, bone turnover, and muscle strength in Chinese adolescent girls. The Journal of Nutrition 2009; 139(5):1002-7.

https://doi.org/10.3945/jn.108.102053

PMid: 19321588 